\title{
LOW COST AUTOMATION USING ELECTRO PNEUMATIC SYSTEM - AN ONLINE CASE STUDY IN MULTISTATION PART TRANSFER, DRILLING AND TAPPING MACHINE
}

\author{
M. Muthukkaruppan and K. Manoj \\ Department of Mechatronics \\ Kongu Engineering College \\ Perundurai - 638 052, India \\ muthuthere@gmail.com,tnxmanoj2@yahoo.co.in
}

\begin{abstract}
This paper discusses the case study and, comparison of productivity of a component using a real time multi stationed AUTOMATED ROTARY TRANSFER LINE used for Drilling, tapping and inspecting a standard block of size $50 \times 50 \times 75 \mathrm{~mm}$ with drill size diameter $5 \times 20 \mathrm{~mm}$ long and tapping the drill by M6 machine Tap. The clamping of the component, part transfer and feed of the drilling machine spindle is done using electro-pneumatics. The total logic of the system is based on Low cost automation with the micro controllers. The following studies are carried out 1 . Time saved by component handling (loading and unloading), using pneumatic clamping, 2. Increase in productivity both qualitative and quantitative, 3. Improved repeatability and accuracy, 4. Less human intervention, indirectly reduction in operator fatigue, 5. Less rejection due to automatic controls, and 6. Minimization of production costs.
\end{abstract}

\section{KEYWORDS}

Automation, Productivity, Electro-Pneumatics, Micro-Controller, Electromagnetic Relays, Reduction Gears

\section{INTRODUCTION}

Mechatronics, which is defined as the synergistic integration of mechanical engineering with electronics and intelligent computer control which had propelled fluid power to overcome many challenges posed by other form of energy technologies. The rapid development of electronic interfacing technology had seen the proliferation of electro-hydraulics and electro-pneumatics devices. Fluid, electric and solar powers are some of the energy technologies used for driving modern automated systems. Of these technologies fluid power is mainly reserved for traditional utilization i.e., hydraulic power is normally used in mechanisms and pneumatic power for sequential automation process.

The technology of 'degree of mechanization' is decided upon the principles of minimization of cost, improved productivity both qualitative and quantitative, improved accuracy, better safety etc., which again is posed with higher initial investments, higher maintenance costs etc., Automation is a higher degree mechanization in which human participation is replaced by mechanical, electrical, fluid power technologies capable of doing physical and even mental work as in the case of CNC machines. In some situations automation also demands accurate sensing, recall, memory storage, physical efforts or movements requires special sensors for controlling the technological processes.

\section{SETUP DETAILS}

A real time multi stationed AUTOMATIC TRANSFER LINE working set up has been fabricated. Drilling, tapping and inspecting on a standard block of size $50 \times 50 \times 75 \mathrm{~mm}$ are performed using above set up. The drill size 
diameter $5 \times 20 \mathrm{~mm}$ deep and countersunk is performed then it is tapped by M6 machine Tap.

The set up created consists penta-stationed prismatic body fabricated using L angles $1 \frac{1 / 4}{4}$ " and channels 4"width. The fixed station is welded to the axle and machined for perpendicularity. The bearings are held in a bearing flange, which is centrally fitted to the axle at the bottom of the fixed station through a roller.

The roller connects the rotary table, where 5 stations are arranged. The indexing mechanism is achieved through limit switches for every $72^{\circ}[1]$. The clamping of the component, part transfer, the feed of the drilling machine spindle is done using pneumatics. The total logic of the system is based on Low cost automation with the micro controllers.

One of the main advantages of rotary indexing is that a part once located in the work holder remains clamped in that position until it has passed completely through cycle.

Rotary indexing tables1, the main type of carrier for work that must pass through at least two and up to more than 20 machining operations, reduce the overall feeding functions of the production sequence to the minimum [1]. Clamping and release of the work pieces, is integrated into the work holder, each takes place but once for the complete machining sequence. No orientation of the work is needed between separate stations. Loading and ejection are limited to the first and between first and last indexing stations respectively and the number of workstations in between is immaterial.

Rotary indexing units can be customized in the shop for a specific duty, mostly as a central component of special purpose machine. Drive can be electric, hydraulic, mechanical or pneumatic depending on what power supply is available or what is in the best interests of uniform operations.

The drive for the rotary table motion is through a prime mover - electrical motor 1440rpm. 2-stage worm reducing gear7 set reduces the speed of the motor. In first stage the reduction ratio is $20: 1$ and in the stage 2 stages the reduction is $70: 1$. The out put rpm is around $1.3 \mathrm{rpm}$. The output worm wheel is connected by roller, which is firmly held in by two bearings at two ends. The rotary table achieves drive from this roller through fastening. The roller is also held firmly by an axle, which is centrally fastened.

\subsection{First Station}

Work is loaded in the hopper and ejected by cylinder 1 to the work holder where it is located.

\subsection{Second Station}

Inspection of overall size of the rectangular block by cylinder 2 , fitted with micro switches. If inspection doesn't confirm to standard the job is rejected using cylinder 3 .

\subsection{Third Station}

Clamping of the component in the work holder by cylinder 4, and drilling and countersinking operation by cylinder 5 . Feed and retract of the drill is through rack and pinion connected to the piston of the cylinder.

\subsection{Fourth Station}

Inspection of the drill hole depth by cylinder 6 , using micro switches is done. If inspection doesn't confirm to drawing standard the component is rejected by cylinder 7 .

\subsection{Fifth Station}

Work piece clamping by cylinder 8 and tapping of the drilled hole by cylinder 9 . Feed and retract of the machine tap is through rack and pinion connected to the piston of the cylinder.

\section{SPECIFICATIONS OF MACHINE}

\subsection{Mechanical}

\begin{tabular}{|l|c|}
\hline Drilling capacity & $12 \mathrm{~mm}$ \\
\hline Stroke length & $100 \mathrm{~mm}$ \\
\hline Spindle speeds & $300,700,1000 \mathrm{rpm}$ \\
\hline Tapping capacity & 3 to $10 \mathrm{~mm}$ \\
\hline Clamping capacity & $100 \mathrm{~mm}$ \\
\hline
\end{tabular}

3.2. Pneumatic

\begin{tabular}{|l|l|}
\hline Cylinder & Single/Double acting \\
\hline DCV & $6.35 \mathrm{~mm}$ \\
\hline FCV & $6.35 \mathrm{~mm}$ \\
\hline FRL & $12.7 \mathrm{~mm}$ \\
\hline
\end{tabular}


3.3. Electrical

\begin{tabular}{|l|ll|}
\hline Microcontroller & AT89C51 \\
\hline Optoisolator & IC 4N35 \\
\hline Relay Driver & IC ULN 2003 & \\
\hline Relay & 12V DC, 5A 12V DC, 20A \\
\hline $\begin{array}{l}\text { DCV (solenoid } \\
\text { actuated) }\end{array}$ & DC 24V, AC 230V & \\
\hline Motor & $\begin{array}{l}1 / 2 \quad h p, \quad 1440 \mathrm{rpm} \quad 1 / 4 \quad \mathrm{hp}, \\
1440 \mathrm{rpm}\end{array}$ & \\
\hline
\end{tabular}

\section{WORKING}

The blank is initially stacked in the hopper where the presence is detected by the proximity sensor. The operation starts with the feeding of blank from the hopper to the indexing table and being placed at the fixture by the actuation of cylinder 1 . Now the indexing occurs and motor is stopped as soon as the limit switch is actuated at $72^{\circ}$. The length and breadth of the blank is verified using a micro switch setup fixed to the end of cylinder 2 . The controller actuates the rejection cylinder depending on the signal from the micro switch.

The blank is again indexed to the next station where the drilling operation is to be performed. First the clamping cylinder clamps the work piece to the fixture. The drilling motor is now turned on and the drill feed is given using a rack and pinion arrangement attached to the cylinder. Now the cylinder is retracted.

In the next station the drill depth is verified by using a set of micro switches attached to the cylinder. The piece is accepted or rejected depending on the signal from the micro switches. Tapping is the operation that is to be performed at the next station. It is same as the drilling station. First the piece is clamped. Then the motor is turned on and tapping feed is given at a very slow speed. A horizontal bar provided between the last and the first station does the unloading of the finished part. The bar slides the work piece out of the fixture.

\section{CONTROLLER}

The controller used here is a Microcontroller, which has a reprogrammable flash memory. The Microcontroller is provided with built-in ROM which avoids any external memory interface. It has four 8-bit ports. These ports can be programmed both as input or output ports as per the requirement.

In this machine, ports are programmed as two 8-bit input ports and two 8-bit output ports. The inputs include the signals from limit switches, reed switches, micro-switches and proximity sensors. The output signal controls the solenoids and motors through relays and driver circuits. The controller is programmed using assembly language to perform the operations depending on the signals from the switches and sensors. The programming is done in a PC and burned into the ROM using a programmer circuit.

\section{ELECTRONIC CIRCUIT}

The micro-controller constitutes the brain of the circuit. It generates the required signals for controlling. External circuits are required to drive the relay depending on the signal. The devices used are opto-isolator, relay driver and relays. Opto-isolator isolates the control circuit from the relay circuit. Control circuit is a low power circuit, whereas the relay circuit is a comparatively high power circuit. Any direct connection between these circuits will destroy the control circuit.

The maximum current the opto-isolator can drain is not enough to drive the relay. So an additional relay driver is required. This relay driver can drain the current required to drive the relay. The relays used are $12 \mathrm{v}$ DC relays of electro-mechanical type. $5 \mathrm{~A}$ relays are used for lower loads like solenoids and 20A relays for higher loads like that of motor.

\section{ELECTRICAL CIRCUIT}

The connections of relays, power supplies and devices like motors and solenoids form the electrical circuit. The circuit includes protection circuits, safety features and provisions for manual controls. Protection circuits includes devices like fuses, circuit breakers, overload protection, overvoltage protection circuits etc., Safety features includes emergency stop button, fault indicators, alarms etc. Provision is also given for manual control of the machine. In case of any malfunctions in the automatic control process, manual control can be adopted. Manual control is also used for maintenance purpose. 


\section{PNEUMATIC CIRCUIT}

The pneumatic circuit comprises of single acting and double acting cylinders, DC valves - single solenoid with spring return, Flow control valves, pressure relief valve, FRL unit and compressors. Double acting cylinders are used for feeding drill bit and tap, where the load is to be handled in the forward and return strokes. Elsewhere single acting cylinders are used.5/2 valves are used for controlling double acting cylinders and $3 / 2$ valves are used for single acting cylinders. Flow control valves 4 are used to control the speed of actuation of cylinders responsible for feeding drill bit and tap. Other accessories like pressure relief valves, FRL unit are used for specific purposes.

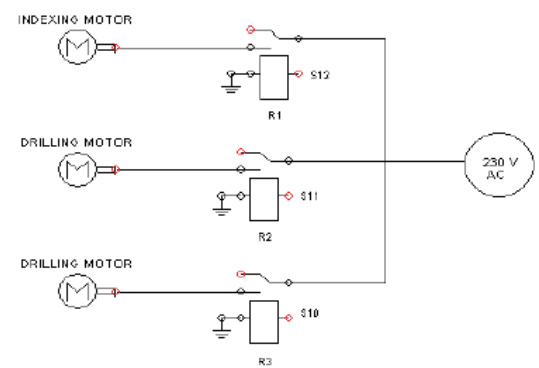

Figure 1 Motor Circuit

\section{CASE STUDIES}

1. Time saved by component loading and unloading: Initially the time study was conducted by loading the component by conventional means manually. The time taken by the operator was around 10seconds for loading and unloading. For clamping using mechanical vice was around 12 seconds. By using the hopper system wherein components are stacked for every 10 cycles the loading and unloading time has considerably reduced to 3 seconds and also the clamping time of the work piece is only 2 seconds, so a cut down of 17 seconds.(Refer Table 1).

Inspection for quality of the work is traditionally performed after the process. This means that any poorquality product has already been produced by the time it is inspected. Incorporating the inspection into the manufacturing process permits the corrections to the process as product is being made. This reduces scrap and brings overall

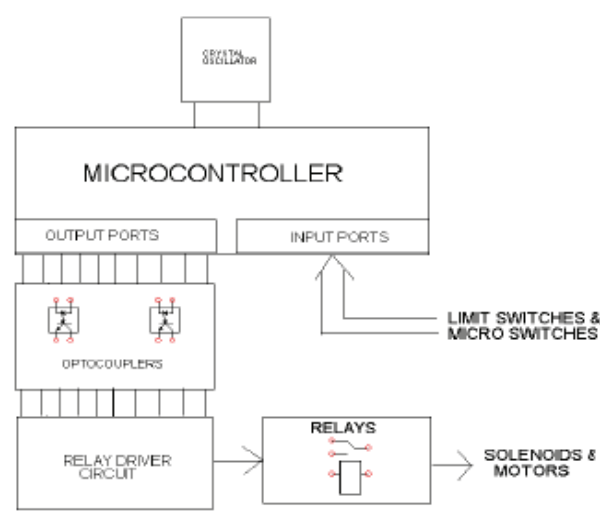

Figure 2 Micro Controller Interface

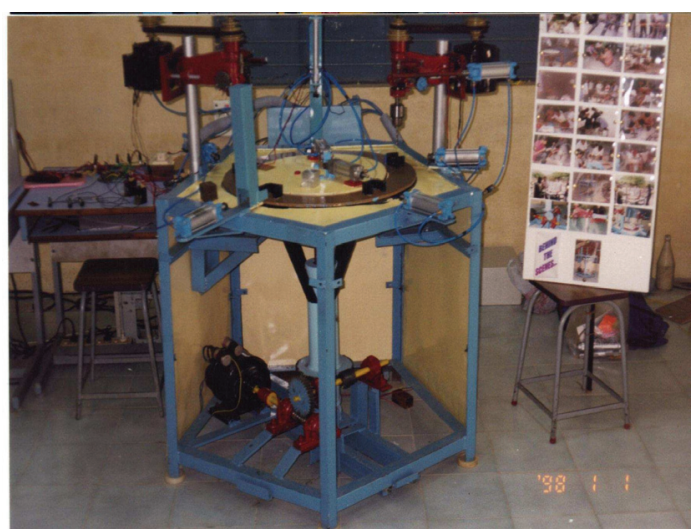

Figure 3 Photograph of Experimental Setup

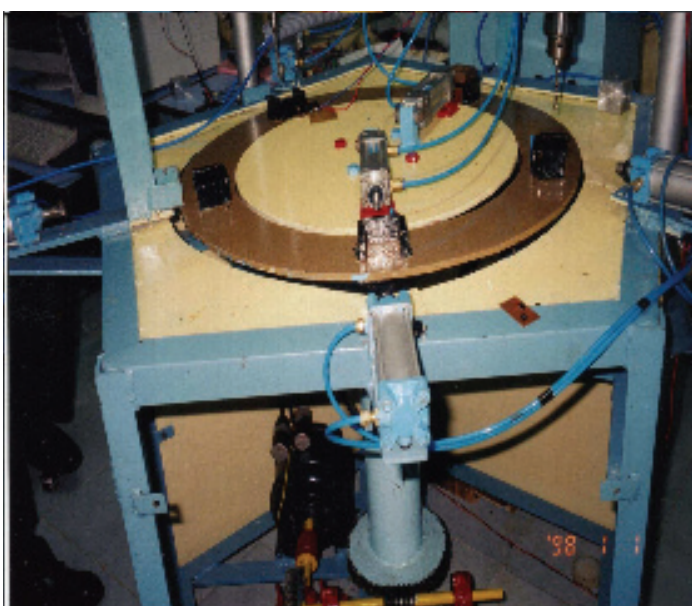

Figure 4 Photo Showing Rotary Indexing Table with Pneumatic Cylinders 


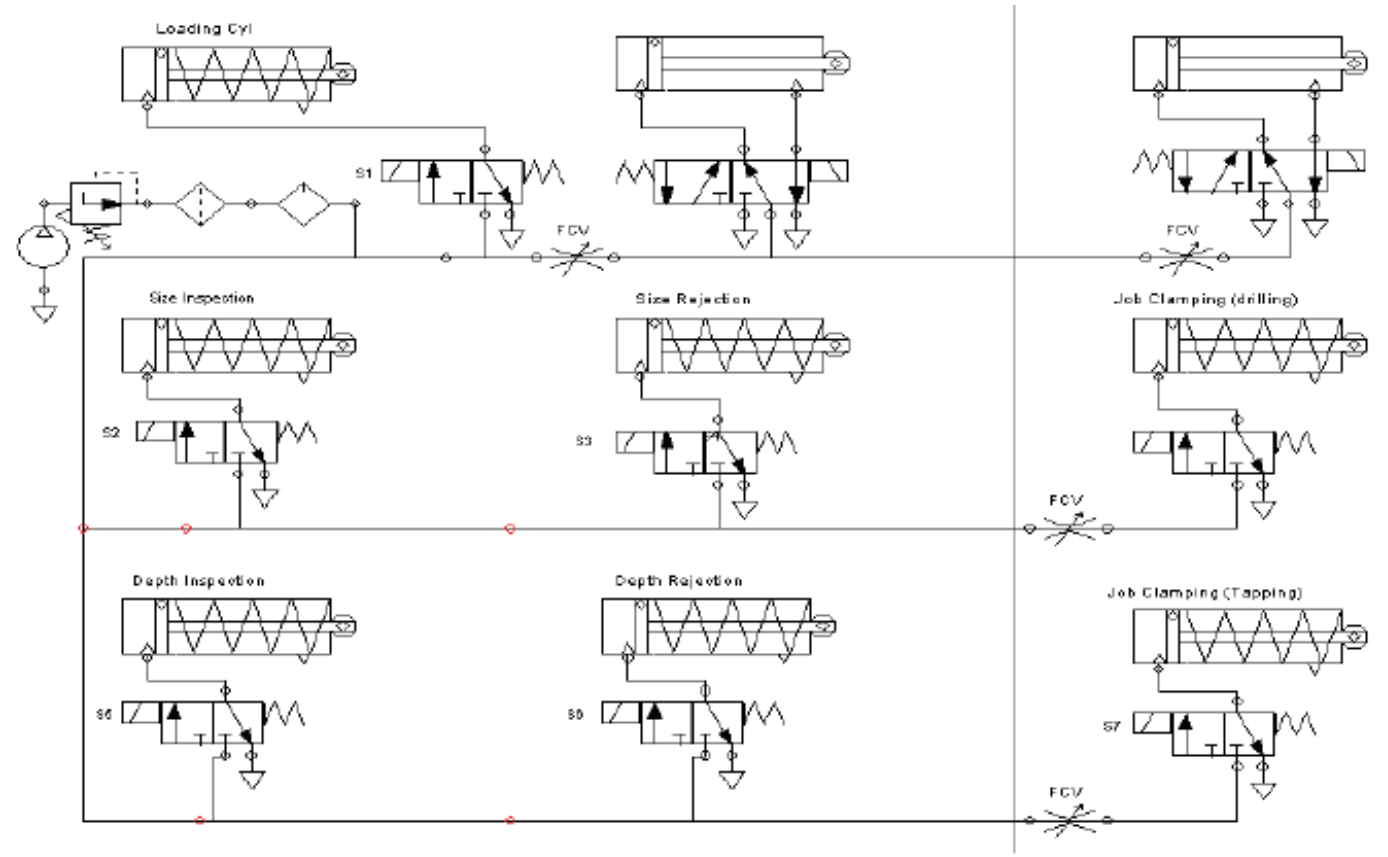

Figure 5 Schematic of Electro Pneumatic Circuit

quality of the job closer to the nominal specifications intended by the designer2 For inspection a separate inspector is required the inspection time is around 3 minutes for each components wherein the component handling, labor cost is again a factor. In the transfer line the inspection is done with the micro switches fitted in the piston end segregates and transfers only the accepted job to the next station. Overall time saved when comparing the standard method of inspection is around 2 minutes and 54 seconds. This process is called On-line inspection.

2. Productivity improvement both qualitative and quantitative 2: Productivity increases by decreasing the lead time of the component, increasing the production rate, reducing WIP.

Manufacturing lead time ${ }^{2}$

$\operatorname{MLT}=\mathrm{N}_{\mathrm{s}}\left(\mathrm{T}_{\mathrm{t}}+\right.$ longest $\left.\mathrm{T}_{\mathrm{o}}\right)$

Where, $\mathrm{N}_{\mathrm{s}}=$ number of stations,

$\mathrm{T}_{\mathrm{o}}=$ operating time.

$\mathrm{MLT}=5(15+10) \mathrm{r}$

$=125 \mathrm{sec}=2$ minutes and $5 \mathrm{sec}$.

\begin{tabular}{|c|l|c|c|c|}
\hline $\begin{array}{c}\text { Station } \\
\text { No }\end{array}$ & Operation & $\begin{array}{c}\text { Setup time } \\
\left(\mathrm{T}_{\mathrm{o}} \mathrm{sec}\right)\end{array}$ & $\begin{array}{c}\text { Operating } \\
\text { time } \\
\left(\mathrm{T}_{\mathrm{o}} \mathrm{sec}\right)\end{array}$ & $\begin{array}{c}\text { Non- } \\
\text { operating } \\
\text { time } \\
\left(\mathrm{T}_{\mathrm{o}} \mathrm{sec}\right)\end{array}$ \\
\hline 1 & Loading & - & 3 & 9 \\
\hline 2 & Inspection & - & 6 & 6 \\
\hline 3 & Drilling & 2 & 10 & 0 \\
\hline 4 & Inspection & - & 6 & 6 \\
\hline 5 & Tapping & 2 & 10 & 0 \\
\hline
\end{tabular}

3. Improved repeatability and accuracy: Half degree accuracy is achieved in indexing the table through the limit switches beneath the fixed table. Repeatability of 0.95 is achieved for indexing operation and the central axis of the job in drilling and tapping operation.

4. Less human intervention: Drastic reduction in the work load is attained through the automation process which directly helps in less operator fatigue. This reduces the labour cost.

5. Less rejection due to automatic controls: Because of high accuracy and repeatability achieved due to automatic control system, rejection of components is reduced. 
6. Minimization of production costs: Increased production rate, reduced production costs, reduced labour costs, reduced WIP, minimises the production costs.

\section{CONCLUSION}

The concept of automated part transfer line fabricated as an experimental setup can be extended to an industrial application with further modification in the manufacturing and assembly process to achieve quality in the machine as per the test charts provided by leading machine tool manufacturer. On a whole, it is concluded that the automation is an inevitable process though the rate at which it should be introduced will have to be carefully planned in order to bring social justice and to accrue economic benefits.

\section{REFERENCES}

[1] Werner Deppert and Kurt Stoll. 'Cutting Costs with Pneumatics' First edition 1988.

[2] Mikell P. Groover. 'Automation, Production Systems and Computer-Integrated Manufacturing' 1987 Prentice-Hall of India.

[3] Ray Asfal. 'Robotics and automation'

[4] Werner Deppert and Kurt Stoll. 'Pneumatic Controls' First edition 1975.

[5] Mike Predko. 'Programming and customizing 8051 Microcontrollers'.2000 Edition

[6] Ramesh S. Gaonkar 'Architecture and interfacing of 8085 Microprocessor' 1998 Edition.

[7] PSG.'Design Data Hand Book' 2000 Edition.

[8] Harry L. Stewart and John M. Storer.'abc is of Pneumatic circuits'.1985Edition. 